\title{
Grandezas: relações lidas no ensino de saberes aritméticos, 1890-1950
}

\section{Quantities: relations read in the teaching of arithmetic knowledge, 1890-1950}

\author{
Deoclecia de Andrade Trindade ${ }^{1}$ \\ Maria Célia Leme da Silva ${ }^{2}$
}

\begin{abstract}
Resumo
Este trabalho é o resultado de uma pesquisa que teve como objetivo analisar as relações das grandezas com os saberes aritméticos, especificamente os números e as frações. Para isso, foram considerados como fontes os programas do ensino primário de São Paulo de 1890 a 1950. Os conceitos de grandeza discreta e contínua (Chambris, 2007); de número concreto e abstrato (Noirfalise, 2007) foram tomados como lente de análise, assim como os movimentos pedagógicos em circulação no período. Pode-se inferir que, àquela época, na escola primária, a ideia de número e operações foi abstraída das grandezas discretas. E o ensino das frações ordinárias e decimais foi proposto via números abstratos, com exceção dos programas de 1925 e 1949/50, nos quais se percebeu que as grandezas discretas e/ou as contínuas passaram a integrar o seu ensino. Ressalta-se que a abordagem do ensino de números e frações relacionadas às grandezas pode ser lida como resultado das ideias advindas do Método intuitivo e da Escola Nova.
\end{abstract}

Palavras-chave: grandezas; números e frações; saberes aritméticos; escola primária

\begin{abstract}
This work is the result of a research that had as objective to analyze the relations of the quantities with the arithmetical knowledge, specifically the numbers and fractions. For this, the primary education programs of São Paulo/Brazil from 1890 to 1950 were considered as sources. The concepts of discrete and continuous quantities (Chambris, 2007); of concrete and abstract numbers (Noirfalise, 2007) was taken as the lens of analysis, as well as the pedagogical movements in circulation in the period. It can be inferred that at that time in primary school, the idea of number and operations was abstracted from discrete quantities. And the teaching of the ordinary and decimal fractions was proposed by abstract numbers, with the exception of the programs of 1925 and 1949/50, in which it was realized that discrete and/or continuous quantities came to integrate their teaching. It is emphasized that the approach to teaching numbers and fractions related to greatness can be read as a result of the ideas coming from the Intuitive Method and the New School.
\end{abstract}

Keywords: quantities; numbers and fractions; arithmetic knowledge; primary school

\section{Considerações Iniciais}

O presente artigo dialoga com o projeto de doutorado em finalização, cujo objetivo é

\footnotetext{
Submetido em: 13/10/2017 - Aceito em: 20/09/2018 - Publicado em: 21/09/2018

1 Doutoranda em Ciências pela Universidade Federal de São Paulo, Campus Guarulhos, Brasil. Email: deo.clecia.1@gmail.com.

2 Doutora em Educação pela Pontifícia Universidade Católica de São Paulo, Brasil. Professora da Universidade Federal de São Paulo, Campus Diadema, Brasil. Email: mcelialeme@ gmail.com.
} 
investigar como se caracterizam as medidas na escola primária de 1890 a 1950. Com o decorrer da investigação, percebeu-se a necessidade de inserir as grandezas em diálogo com as medidas, já que na escola as "medidas", tomadas como saberes elementares matemáticos ${ }^{3}$ que se remetem ao ensino do valor de tamanhos, distâncias, capacidades, etc., dependem da qualidade que se mensura (comprimento, quantidade de elementos, volume etc.).

Em vista dessa trajetória de pesquisa, este estudo pretende analisar como as grandezas foram inseridas e como se relacionavam aos saberes aritméticos, especificamente ao ensino dos números, às quatro operações e às frações (ordinárias e decimais) na escola primária de São Paulo, no período de 1890 a 1950. A análise da inserção se atém a investigar em que momento e como as grandezas estão alocadas no ensino de saberes aritméticos. Foram considerados como fontes de pesquisa os programas de ensino de São Paulo, em especial as orientações que se referiam à matéria Aritmética no período de 1890-1950.

A opção por considerar o estado de São Paulo nesse período se justifica pela proclamação da República pelo Marechal Deodoro da Fonseca, em 1889, pois nesse cenário, o Brasil lidou com várias mudanças, em diversas esferas da sociedade, e São Paulo foi o primeiro estado que, após debates públicos sobre a educação, em 27 de novembro de 1893 aprovou um novo modelo educacional: os grupos escolares obrigatórios para crianças de 8 a 12 anos (Souza, 2009).

Com a criação dos grupos escolares, foram instituídos novos programas de ensino, os quais definiam conjuntos de matérias e conteúdos escolares a serem seguidos nas instituições de ensino primário. Até os anos de 1950, sete programas foram divulgados em São Paulo (1894; 1905; 1918; $1921^{4} ; 1$ 1925; 1934; e 1949-1950), cada um com suas peculiaridades e conjuntos de matérias específicos, que, ao longo do período, mudaram entre os anos escolares.

Por exemplo, o programa de educação primária paulista de 1894 oficializou matérias que deveriam estar presentes nos quatro anos da escola (cada ano com duas séries), com as seguintes rubricas: Escrita, Aritmética, Desenho, Formas, Trabalho Manual, Modelagem, Sistema Métrico, Geografia e Geometria. Já o programa de 1934, a educação primária também com quatro anos de duração, dividiu-se em três subconjuntos de disciplinas - o primeiro denominado Disciplinas de Expressão, com as matérias: Leitura, Linguagem Oral, Linguagem Escrita, Desenho, Trabalhos Manuais e Música; o segundo denominado Iniciação Matemática, com as matérias para o $1 .^{\circ}$ e o $2 .^{\circ}$ ano: Cálculo e Formas, e para o $3 .^{\circ}$ e o $4 .^{\circ}$ ano:

\footnotetext{
${ }^{3}$ Os saberes elementares matemáticos são entendidos como os primeiros passos, a base inicial de conhecimentos em matemática, organizada para ser ensinada aos alunos dos primeiros anos escolares, em consonância com as vagas pedagógicas a que fica submetido o sistema escolar (Valente, 2015). Hofstetter e Schneuwly (2017) consideram os saberes como os conhecimentos, suas propriedades e enunciados coerentes, reconhecidos por uma comunidade científica ou profissional.

${ }^{4}$ O programa de 1921 foi organizado em somente dois anos, ao invés de quatro. E, como sua vigência foi curta, de somente quatro anos, ele não será analisado no presente estudo.
} 
Aritmética $^{5}$ e Geometria; e o último subconjunto, chamado Noções Comuns, que tratavam de História e Geografia.

O período abrangido pela análise aqui exposta é rico em movimentos de reformas educacionais em discussão no âmbito brasileiro. Dois deles tiveram realce: o primeiro, proveniente de ideias do método intuitivo / lições de coisas, que tomaram o centro das discussões pedagógicas que circulavam a época, teve Rui Barbosa como um dos protagonistas. A educação pelas coisas foi evidenciada a partir do final do século XIX, com a divulgação de que "somente esse método poderia triunfar sobre o ensino verbalista, repetitivo, enraizado na memória e nas abstrações inúteis praticado nas escolas de primeiras letras do Império" (Souza, 2000, p.13).

Assim, contrário ao ensino tradicional centrado no professor e com ênfase na memorização e nos processos repetitivos,

o método intuitivo, conhecido também como lições de coisas, consistiu no núcleo principal da renovação pedagógica. Fundamentado especialmente nas ideias de Pestalozzi e Froebel, pressupunha uma abordagem indutiva pela qual o ensino deveria partir do particular para o geral, do conhecido para o desconhecido, do concreto para o abstrato. (Souza, 2000, p. 12)

No Brasil, na virada dos séculos XIX e XX ainda se encontrava no sistema educacional a presença desses ideais. No entanto, a partir da década de 1920, o ideário da Escola Nova, tendo como um dos propulsores Lourenço Filho, começou a ocupar um papel importante. Entre suas propostas, destacaram-se novos fins e meios de aplicação científica, que visaram a outra organização dos estabelecimentos, à transformação dinâmica do ensino passivo para o ensino ativo, que devia ser baseado nos interesses naturais da criança, no trabalho em cooperação e globalizado, numa escola do fazer, praticar a vida, no lugar da escola do ouvir (Lourenço Filho, 1930).

Entre os propósitos desse novo ideário estava a pedagogia científica, que adotava os processos e os métodos da psicologia experimental, e destacava a observação, a experiência do cotidiano e os centros de interesse da criança, com o ensino moldado pela intenção de aprender e com o uso de atividades referenciadas na vida,

Na produção dessas condições, a redefinição do conceito de atividade deveria ter um papel central, fazendo com que as práticas escolares passassem a ser reguladas por normas distintas daquelas que prescreviam a arte de bem ensinar como boa cópia de modelos e a arte de bem aprender como exercício das faculdades da alma [ênfase no original]. (Carvalho, 2000, p. 115)

O exercício das faculdades da alma, segundo a autora, era um ensino que priorizava "a prática que se materializa em outras práticas; práticas nas quais a arte de aprender formalizase como exercício de competências bem determinadas e observáveis em usos escolarmente

\footnotetext{
${ }^{5}$ No programa de 1934 a nomenclatura da matéria que se refere aos saberes aritméticos, a qual integra as disciplinas de iniciação matemática, foi alterada: passou a se chamar Cálculo, no $1 .^{\circ}$ e no $2 .^{\circ}$ ano; e voltou a ser chamada de Aritmética no $3 .^{\circ}$ e no $4 .^{\circ}$ ano.
} 
determinados" (Carvalho, 2000, p. 113).

Importante evidenciar, de modo geral, que, ao considerar o ensino de saberes elementares matemáticos na escola primária, esses movimentos pedagógicos, decorridos entre o final do século XIX e meados do século XX, engendravam propostas externas e de âmbito geral para uma reforma educacional. As mudanças que podem ter sido geradas no contexto do ensino das matemáticas se deviam aos princípios vindos de fora (sentido amplo educacional) para dentro (os saberes matemáticos distribuídos nas distintas matérias).

Pensar este contexto, diante dessas reformas pedagógicas, significa analisar os saberes aritméticos, especificamente, neste estudo, as grandezas em relação aos números e às frações, a partir da perspectiva de que a pedagogia, ao se tratar do ensino primário, não é um lubrificante para o ensino, mas parte constituinte do processo (Chervel, 1990), que modifica a forma como os saberes são mobilizados.

Nesse sentido, considera-se como proposição que os saberes matemáticos na educação elementar foram mobilizados de modos distintos a partir da circulação de ideias das vagas pedagógicas ${ }^{6}$, como a Pedagogia Moderna e o método intuitivo, e a Escola Nova. Contudo, antes de adentrarmos no exame aos programas para a discussão de como essas propostas alteraram a relação das grandezas com os saberes aritméticos, uma questão emergiu: Que elementos seriam necessários identificar, para analisar a relação das grandezas com o ensino dos saberes aritméticos?

\section{As grandezas: construção de uma lente para análise}

Para a continuidade da construção do enredo tomado nesta empreitada, foi preciso constituir uma lente que nos auxiliasse a visualizar as grandezas no contexto dos saberes aritméticos. Nesse sentido, dois artigos foram importantes. O primeiro, da pesquisadora Christine Chambris, Petite histoire des rapports entre grandeurs et numérique dans les programmes de l'école primaire (2007), a qual expôs o estatuto epistemológico das grandezas como complexo, justamente por compor uma espécie de interface entre a matemática e a realidade.

De acordo com Chambris (2007), os discursos teóricos sobre as grandezas distinguem três níveis: objeto, grandeza e medida. Em relação ao objeto, é necessário saber que dois objetos são ditos "iguais", do ponto de vista de uma qualidade, se têm a mesma grandeza. Ou seja, ao considerar dois objetos, pode-se pensar que eles sejam iguais, quando o valor mensurado em ambos, sob um ponto de vista, é igual. Por exemplo, duas cestas com 12 bolas

\footnotetext{
${ }^{6}$ A expressão tem sido empregada em estudos do GHEMAT, como sinônimo de movimento, de fluxo, de transformação de um dado tempo por meio da propagação e ampla aceitação de doutrinas, ideais, filosofias pedagógicas, analisadas, sobretudo, pelos historiadores da educação, resultando no estabelecimento de marcos cronológicos que identificam a prevalência da divulgação destes movimentos, carregados do espírito de transformação. Glossário (2016) disponível em https://repositorio.ufsc.br/handle/123456789/158952.

7 "Pequena história das relações entre grandezas e números nos programas da escola primária".
} 
ou dois recipientes que comportam 10 litros de água cada. No primeiro exemplo, a qualidade analisada foi o número de bolas, que em ambas as cestas têm a mesma grandeza (12 bolas); no segundo caso, a qualidade observada foi a capacidade dos recipientes, que também têm a mesma grandeza (10 litros).

Esse valor numérico "chama-se de medida de um objeto ou de uma grandeza, um número (caracterizado de maneira diferente de acordo com as teorias)". Ressalta-se que, "para uma determinada qualidade, um objeto tem várias medidas enquanto possui apenas uma grandeza" (Chambris, 2007, p. 15). Para ilustrar, voltemos aos mesmos exemplos: 12 bolas é uma grandeza e, neste caso, 12 seria sua medida, se a unidade fosse unitária, e 1, se a unidade fosse dúzia. Já para o recipiente com 10 litros, 10 seria sua medida, se o litro fosse considerado como unidade, e 10.000, se a unidade tomada fosse milímetro.

Pode-se dizer que os níveis em questão - objeto, grandeza e medida - podem ser considerados do ponto de vista do discreto (como no caso da cesta com bolas) ou do contínuo (como o caso do recipiente com água). Teoricamente, no contexto do discreto, Chambris (2007) destaca que o objeto "geralmente chamado de coleção, é um subconjunto finito de um conjunto de 'coisas'. Uma grandeza discreta é uma classe de equivalência de coleções equipotentes. A palavra quantidade é, muitas vezes, utilizada para designar uma grandeza discreta" (p. 15). Assim no nosso exemplo, o objeto é o conjunto de bolas, a grandeza pode ser tomada como a classe de equivalência dos conjuntos de bolas que têm a quantidade igual a 12.

No caso do contínuo, diz-se que o objeto é o recipiente, e o conteúdo do recipiente determina uma grandeza: a classe de equivalência dos recipientes que tenham esse conteúdo, como no caso dos 10 litros. Assim, tanto 12 bolas quanto 10 litros são grandezas, pois ambos constituem um "rótulo" que classifica uma classe de equivalência, seja das cestas com 12 bolas ou dos recipientes que contêm 10 litros (Chambris, 2007).

A autora, em seu estudo, deixa claro que grandeza e medida podem ter distintas definições; entretanto, ela considera as grandezas discretas (12 bolas) e as grandezas contínuas (10 litros) como grandezas mensuradas, porque constituem um rótulo, respectivamente, para a classe do conjunto de bolas que possuem essa quantidade ou a classe de recipientes com essa capacidade. Posto isso, pode-se dizer que o número que expressa a medida das grandezas pode representar uma grandeza discreta ou contínua, a depender do objeto que se mede, mas em ambas as situações, para a autora, o número expressa grandezas mensuradas.

O segundo artigo que nos ajudou a construir a lente de análise intitula-se Calculer avec les grandeurs: l'usage des unités dans les calculs ${ }^{8}$, no qual Noirfalise (2007) discute o lugar das grandezas no ensino e destaca que a discussão sobre grandezas na educação não é nova, visto que é encontrada em textos antigos, como o livro escrito por Bernard Lamy e publicado em 1741, com o sugestivo título: Elements de mathématiques ou traité de la

8 "Calcular com as grandezas: o uso das unidades nos cálculos". 
grandeur en général. Noirfalise (2007) evidencia que, embora a matemática possa se desenvolver sem referência à grandeza, "historicamente, é a partir de um trabalho sobre as quantidades que foram construídos conceitos e teorias matemáticas" (pp. 22-23). Para tanto, o autor considerou dois tipos de números: os números concretos e os números abstratos:

Quando um número é enunciado sem indicar a natureza das unidades que representa, ele é nomeado de número abstrato; caso contrário, ele é chamado de número concreto; assim o 7 é um número abstrato, e quando é dito 7 litros, o número é concreto. Nós mencionamos essas denominações porque há um risco de encontrá-los nas antigas obras aritméticas, mas devemos advertir que a segunda tende a dar uma ideia inexata. Um número concreto não é um número, é uma grandeza. Quando dizemos 7 litros, o número é 7, a palavra litro completa a ideia, mas não a altera. (Noirfalise, 2007, p. 25)

Percebe-se que a omissão ou a presença da natureza das unidades é o que diferencia o número abstrato do número concreto. No entanto, é possível correlacionar a citação "número concreto é uma grandeza" aos exemplos do estudo de Chambris (2007), ou seja, os números concretos expressos por número e unidade são as grandezas mensuradas, as quais podem ser discretas ou contínuas. Logo, diferentemente do número concreto (ou grandeza mensurada), o número abstrato é um conceito matemático, genérico e não necessita obrigatoriamente representar uma grandeza mensurada.

Em suma, pode-se dizer que os números concretos designam grandezas mensuradas, sejam elas discretas ou contínuas, enquanto os números abstratos são tratados independentemente das grandezas. É a partir dessa lente que os programas de São Paulo foram analisados. Um exame geral nos programas leva a observar que os números concretos (Noirfalise, 2007) ou as grandezas mensuradas (Chambris, 2007) poderiam ser verificados nas indicações em que as unidades (discretas ou contínuas) estariam representadas, e os números abstratos (Noirfalise, 2007), quando nenhuma unidade fosse chamada a compor o número. Nesse sentido, as discretas são representadas pela menção à quantidade de elementos de uma coleção de objetos ( 2 bolas, 5 lápis, 4 pedras.); as contínuas, pelos indícios da referência de medidas de objetos (4 cm, 6 litros, $5 \mathrm{~kg}$, 1/2 lápis, 1/4 de laranja); e os números abstratos, sem expor ligação a unidades $(2,8,1 / 3,4+6)$.

Posto isto, considerando a leitura dos programas de ensino de São Paulo no período 1890-1950, de modo a compreender como os números, as quatro operações e as frações se relacionaram a essas grandezas mensuradas (números concretos), algumas perguntas surgem: a depender dos conteúdos ensinados - números, suas operações ou frações -, quais as relações entre as grandezas e os seus ensinos? Como as grandezas mensuradas (ou números concretos) foram chamadas a integrar o ensino dos saberes aritméticos? Como as ideias pedagógicas alteraram a mobilização das grandezas mensuradas no ensino de tais saberes?

Vale retomar que os saberes matemáticos, diante da circulação de ideias pedagógicas, podem ganhar novas interpretações, ao pensar no contexto da escola e, mais especificamente, nos anos iniciais de escolaridade. Como já dito, ressalta-se a proposição de que tais saberes foram mobilizados e reconfigurados com a chegada de vagas pedagógicas, o ensino intuitivo e a escola nova. 
Em busca de respostas às questões supracitadas, para a análise consideraram-se inicialmente os números (naturais e decimais) ${ }^{9}$ e as operações, e em seguida as frações (ordinárias e decimais), de modo examinar como as grandezas foram abordadas na educação primária, em perspectiva histórica.

\section{As grandezas nas prescrições do ensino dos números e operações}

Uma análise global da matéria Aritmética na escola primária, entre os anos de 1890 e 1950, indica que seu programa, de modo geral, se remetia ao ensino dos números (naturais e decimais), com seus cálculos e operações, às frações ordinárias e decimais e ao sistema de pesos e medidas, muito embora, com o passar dos anos, apresentassem distinções em relação à ordem dada aos conteúdos ou às orientações para o ensino.

Os números naturais e as operações foram abordados na matéria Aritmética desde o primeiro ano, iniciando com os números menores. Por exemplo, o programa de 1894 no primeiro ano sugeria o ensino das operações até 10; no terceiro ano tinha a tabuada de adição, subtração até 120 e a tabuada de multiplicação e divisão até 12. Percebe-se, assim, uma marca do ensino intuitivo, pela necessidade de considerar primeiro os números menores, próximos do ambiente do aluno, e à medida que as séries e os anos de escolaridade fossem avançando, o valor numérico iria aumentando.

Os números decimais e suas operações foram, em geral, propostos explicitamente a partir do terceiro ano, como no caso do programa de 1925: "Numeração falada e escrita. Números inteiros e decimais. Explicar o que não altera um decimal. Tornar um número inteiro ou decimal - 10, 100, 1000, etc. vezes maior ou menor" (3. ${ }^{\circ}$ ano). Ou no programa de 1894: “Addicção, subtracção, multiplicação, divisão de números decimaes" (4. ${ }^{\circ}$ ano). Desse modo, no que se refere aos números, pode-se dizer que o ensino dos naturais antecedia o ensino dos decimais.

Os programas de São Paulo, destinados aos grupos escolares, símbolos de uma nova proposta educacional republicana, expõem consigo "vestígios ${ }^{10 "}$ do método intuitivo ou das lições de coisas, muito propagado no final do século XIX, e com eles a necessidade de inserção de "coisas" no ensino dos números. As "coisas" passam a representar coleção de objetos, e os números representam a medida de tais coleções, como o programa de 1894 recomenda: "Contar até 50 sempre com auxílio de objetos" (1. ${ }^{\circ}$ ano, 2. ${ }^{a}$ série).

De forma similar, nas indicações do ensino das quatro operações com números

\footnotetext{
${ }^{9}$ Nos programas de Aritmética quase não se apresentam de modo explícito as expressões Números Naturais e Números Decimais, porém, pelo contexto e exemplos postos pode-se inferir que se trata dos referidos números em questão.

${ }^{10}$ De acordo com Bloch (1998), "o conhecimento de todos os fatos humanos no passado, da maior parte deles no presente, possui como primeira característica a de ser... um conhecimento por vestígios.... O que queremos dizer, na prática, com documentos, se não um 'vestígio', o que equivale a um sinal perceptível aos sentidos, mas que deixou um fenômeno impossível de ser detectado em si mesmo? [ênfase no original]" (p. 44).
} 
naturais nos primeiros anos dos programas, identificam-se indicativos do uso dos objetos a partir das prescrições: "Somar, diminuir, multiplicar e dividir praticamente até 10 com auxilio de objetos" (Programa das Escolas Preliminares, 1894, 1. ano, 1. a série); "Rudimentos das primeiras operações pelos meios concretos, com auxílio de taboinhas ou de tornos de sapateiro" (Programa de Ensino para os Grupos Escolares e Escolas-Modelos, 1905, 1. a ano); "Rudimentos das primeiras operações, pelos meios concretos. Conhecimento directo dos grupos 2, 3, 4 e 5 por um simples golpe de vista" (Programa de Ensino para os Grupos Escolares, 1918, 1. ${ }^{\circ}$ ano); "Ensinar por meio de grupos de objetos, os números de 1 a 10. Exercícios concretos, cálculos com auxílio de estampas e problemas orais com esses números abrangendo as quatro operações"; e "Exercícios com auxílio de tornos, tabuinhas, sementes, desenhos, estampas, etc. para a aprendizagem das quatro operações sobre os números de 1 a 10" (Programa de Ensino do Curso Primário para os Grupos Escolares e Escolas Isoladas, 1925, 1. ${ }^{\circ}$ ano).

A partir dessas prescrições, nota-se que a recomendação do uso de objetos concretos, advinda das ideias do método intuitivo para introduzir o ensino dos números naturais e das operações nos primeiros anos do curso primário permaneceu no período analisado ${ }^{11}$. E, nesse contexto, trabalhar as coisas em relação aos saberes aritméticos pode ser lido como a condução do ensino pelas grandezas mensuradas. Trata-se do momento da inserção do conceito de grandezas discretas no programa, mesmo que de forma implícita, ao abordar a ideia de número e as operações pelas coisas -1 bola, 5 tabuinhas, 3 sementes +5 sementes.

Vale considerar que, apesar de o termo "grandezas" não ser referenciado em nenhum desses programas para o $1 .^{\circ}$ ano escolar, no decorrer do período, implicitamente a noção de grandeza foi ganhando visibilidade mais acentuada, com evidência nos programas de 1925 e de 1949/50, em que se propunha ensinar, por meio de "grupos de objetos, os números 1 a 10. Exercícios concretos, cálculos com auxílio de estampas e problemas orais com esses números abrangendo as quatro operações", em 1925; e a designação de "ideia de quantidade, noção de unidade e de coleção", em 1949/50.

No caso do programa de 1949/50, ao contrário do que foi proposto anteriormente, "a ideia de quantidade, tamanho e peso" (1. ${ }^{\circ}$ ano) se tornou o ponto inicial do ensino dos saberes aritméticos. Em seguida, no ensino de numeração para o trabalho com contagem, se propõe a "noção de unidade e de coleção". Essa diferença parece ser um indício de que o ensino das grandezas começa a ser sistematizado e tomado como elemento introdutório para os saberes aritméticos, haja vista que quantidade, tamanho e peso ou mesmo a noção de unidade e de coleção são aspectos que permeiam a ideia de grandeza.

Pode-se ainda constatar que as grandezas discretas foram o ponto de partida para o ensino dos números naturais e suas operações. Noutra linguagem, os primeiros números

\footnotetext{
11 A dissertação de Pinheiro (2013), que objetivou pesquisar acerca das transformações do significado do conceito de número, ao longo do tempo (de 1880 a 1970), apontou entre os resultados indícios de que o ensino de número era viabilizado pela contagem de objetos. Este estudo avança, ao mobilizar as grandezas discretas ou números concretos relacionados ao ensino dos saberes aritméticos.
} 
estudados (os naturais) no primeiro ano escolar enquadravam-se inicialmente na categoria de números concretos, visto que, a todo tempo, são prescritos com o "auxílio" de objetos. Assim, infere-se que, em relação ao ensino dos números naturais, as propostas do método intuitivo e o ensino pelas coisas tomaram os números concretos, ou seja, as grandezas discretas, de modo a trabalhar a partir delas a ideia dos números naturais e suas operações.

Essa observação é reforçada pelo aspecto de que, ainda no primeiro ano, após a referência ao ensino dos números apoiado nas coisas, ou no uso de objetos, identifica-se a prescrição dos números abstratos, como nos casos: "Ler e escrever números e aprender a ler os mappas de números. Uso dos signaes $+,-, \mathrm{x}, \div,=$, praticamente, nas differentes combinações" (Programa de Ensino para os Grupos Escolares e Escolas-Modelos, 1905, 1. ${ }^{\circ}$ ano); “d) Contar de dez em dez até 100. e) Exercicios sobre as quatro operações até 10" (Programa de Ensino para os Grupos Escolares, 1918, 1. ${ }^{\circ}$ ano); "Leitura e escrita de números e uso dos sinais das quatro operações e de igualdade" (Programas Mínimos do Curso Primário para os Grupos Escolares, 1934, 1. ${ }^{\circ}$ ano); e "Exercícios com números abstratos, efetuando oralmente todas as combinações possíveis até 10" (Programa de Ensino do Curso Primário para os Grupos Escolares e Escolas Isoladas, 1925, 1. ${ }^{\circ}$ ano).

Em continuidade, a análise dos programas referentes aos anos posteriores $\left(2 .^{\circ}\right.$ ano, $3 .^{\circ}$ ano e $4 .^{\circ}$ ano) de escolaridade, no que diz respeito aos vestígios das grandezas discretas, indica que a orientação de uso de objetos praticamente desaparece dos programas e volta a ser referenciada apenas no programa de 1925, para o segundo ano. Ademais, fazia-se referência a uma proposta de um ensino prático, sem especificar como se daria tal prática. Por exemplo: "Estudo suplementar: problemas e questões práticas" (Programa das Escolas Preliminares, 1894, 2..$^{\circ}$ ano); "Estudo prático de numeração oral e escrita" (2. ano, 1918); Explicação das unidades, dezenas, centenas e milhares por meio concreto (Programa de Ensino do Curso Primário para os Grupos Escolares e Escolas Isoladas, 19252. ano,). Ou seja, pode-se inferir que, a partir do segundo ano de escolaridade, para o ensino dos números naturais, os programas abandonaram as grandezas discretas, especificando particularmente um estudo pautado nos números abstratos.

Diante do exposto até o momento, da análise aos números, o conceito de grandezas discretas caminhou num movimento crescente de introdução e suporte para o ensino dos números naturais e de suas operações, no período analisado. Isso permite concluir que o ensino dos números naturais se amparou no contexto das grandezas discretas. Nota-se nas orientações que a marcha do ensino dos números naturais, no primário, partia dos números concretos, com as grandezas discretas chamadas a auxiliar, mesmo que de modo implícito. Nessa trajetória, o ensino seguia gradualmente para o trabalho com o abstrato.

O estudo dos números concretos no ensino de saberes aritméticos pode ser lido como resultado dos debates advindos das vagas pedagógicas. Inicialmente, com o método intuitivo/lições de coisas, como destacado na introdução, se divulgava um ensino articulado a coisas e objetos, para, aos poucos, ir trabalhando a abstração. E em seguida, com a Escola Nova, defendia-se, para além de objetos, o uso de atividades aproximadas a aspectos da vida. 
O que leva, em ambos os casos, a corroborar a inserção das grandezas discretas.

E os números decimais? Como eles eram apresentados nos programas? Identifica-se, assim como nos naturais, um suporte das grandezas para o seu ensino e, neste caso afirmativo, qual grandeza foi chamada a integrar? Ao examinar os programas, percebe-se que os números decimais se imbricavam ao ensino das frações decimais; por esse motivo, essa análise será posta no próximo tópico.

\section{Grandezas no ensino das frações e suas operações}

O exame dos programas de Aritmética de 1894 e 1905 mostra que a noção de fração iniciava a ser trabalhada no segundo ano. A partir de 1918, as primeiras noções passaram a ser apresentadas já no primeiro ano. Em ambos os casos, abordavam-se apenas de modo introdutório, dando uma ideia do que seja fração: “As quatro operações até 100, inclusive conhecimentos de 1/2,1/3, 1/4, etc" (Programa de Ensino para os Grupos Escolares e Escolas-Modelos, 1905, 2. ${ }^{\circ}$ ano); "Exercicios oraes e escriptos sobre os calculos do mappa de numeros, inclusive exercicios sobre fracções" (Programa de Ensino para os Grupos Escolares, 1918, 1. ${ }^{\circ}$ ano); e "Noção do dobro e metade" (1. ${ }^{\circ}$ ano, 1949/50).

As primeiras prescrições para o ensino de frações, de modo geral, remetiam-se às frações ditas ordinárias, aquelas que representam as partes de uma unidade, como 1/2, 1/4, $2 / 5$, para depois passar às chamadas decimais, frações em que o denominador é uma potência de 10 , como $1 / 10$ e $3 / 100$. E, por fim, os programas sugeriam para o quarto e/ou quinto ano (no caso do programa de 1949/50) o ensino da transformação das frações decimais em ordinárias e vice-versa.

Com base nas prescrições dos primeiros programas analisados, de 1894 a 1918, a saber: "Fracções ordinarias homogeneas: somma e subtracção. Fracção decimal: ler e escrever os números decimaes; somma e subtracção" (Programa das Escolas Preliminares, 1894, 3. ${ }^{\circ}$ ano); "As quatro operações até 100, inclusive conhecimentos de 1/2, 1/3, 1/4, etc" (Programa de Ensino para os Grupos Escolares e Escolas-Modelos, 1905, 2. ${ }^{\circ}$ ano); e "Exercicios oraes e escriptos sobre os calculos do mappa de numeros, incluvisé exercicios sobre fracções" (Programa de Ensino para os Grupos Escolares, 1918, 1. ${ }^{\circ}$ ano), é possível verificar que o ensino das frações se remetia aos números abstratos, ou seja, o ensino da fração pela fração, pois não houve menção a coisas ou objetos. Não há referências explícitas das frações ligadas às unidades ( $1 / 2$ laranja, $1 / 4$ de bolo) para abordar as frações, diferentemente do que se observa na instrução dos números naturais.

Ao considerar o programa de 1925, de pronto, nota-se que as prescrições se alteraram em dois contextos. Primeiro porque é nesse programa que o termo "grandeza" apareceu de forma explícita: "Calcular mentalmente o valor de certa fração de uma grandeza dada, e viceversa" (Programa de Ensino do Curso Primário para os Grupos Escolares e Escolas Isoladas, 1925, 3. ${ }^{\circ}$ ano); e "Grandezas direta e inversamente proporcionais. Regras de três simples. Método da unidade" (Programa de Ensino do Curso Primário para os Grupos 
Escolares e Escolas Isoladas, 1925, 4. $^{\circ}$ ano). Contudo, o termo não veio explicitar o mesmo que se observava antes: a palavra "grandeza", ao que se nota, referia-se apenas ao valor numérico, sem associação a objetos e coisas, ou seja, no sentido geral, sem necessariamente remeter-se ao cenário das quantidades discretas ou contínuas, como visto em situações anteriores, em que se consideraram os números concretos para abstrair a noção de número.

O segundo contexto observado no programa de 1925 é o destaque da noção de fração no primeiro ano, intercalada aos conteúdos de números e operações, com a proposta de que seja trabalhada a noção de 1/2, dando como exemplo o meio litro. E, nas indicações, orientouse que as frações fossem abordadas de modo concreto, "fragmentando em partes iguais, uma tira de papel, uma varinha, uma laranja, etc" (Programa de Ensino do Curso Primário para os Grupos Escolares e Escolas Isoladas, 1925, 1. ${ }^{\circ}$ ano). Ou seja, foi no programa de 1925 que pela primeira vez apareceram as frações associadas ao número concreto, o que revela a relação das frações com as grandezas contínuas (tira de papel, varinha, laranja), já que, como visto nos programas anteriores, as frações foram tomadas sem referência às grandezas.

Em continuidade à análise do programa de 1925, no terceiro ano as frações ordinárias faziam referência à divisão de uma tira de papel na metade, ou de uma laranja em quatro pedaços, e ainda propunha indicações que evidenciavam que "o conhecimento concreto dos submúltiplos do metro e de outras medidas do mesmo sistema, facilitará a aquisição de uma noção exata de fração decimal" (Programa de Ensino do Curso Primário para os Grupos Escolares e Escolas Isoladas, 1925, 3. ${ }^{\circ}$ ano). Tais indicações possibilitam verificar que o ensino devia estar relacionado aos números concretos e às grandezas contínuas (1/4 laranja, $1 / 2$ tira de papel).

Assim, a proposta de 1925 demonstrou pela primeira vez a relação das grandezas contínuas com as frações, pois, no caso do terceiro ano, o estudo dos submúltiplos do metro (grandezas contínuas) daria suporte à compreensão da ideia de fração decimal. Esse contexto sugeria que as subpartes do metro: 1/10 (1 decímetro), 1/100 (1 centímetro) e 1/1000 (1 milímetro) fossem consideradas para o ensino das frações decimais.

Ao avançar para o quarto ano, as orientações se mantiveram no mesmo sentido de abordá-las com associações às grandezas:

Procurará sempre meios concretos para explicar os processos dos cálculos sobre frações ordinárias, levando os alunos a descobrir as respectivas regras. Assim, representando por exemplo $23 / 4$ por meio de 2 laranjas inteiras e $3 / 4$ de outra, se dividirem as inteiras em quartos, acharão todo $11 / 4$ e facilmente deduzirão a regra dessa redução. Tomando-se $4 / 5$ de um retângulo que se dividiu em cinco faixas verticais e subdividindo-o claramente a equivalência das frações $4 / 5$ e 12/15 ... concluirão que uma fração ordinária não se altera, multiplicando-se ou dividindo-se ambos os termos por um mesmo número. E de modo análogo, poderemos explicar as outras reduções e operações (Programa de Ensino do Curso Primário para os Grupos Escolares e Escolas Isoladas, 1925, 4. $^{\circ}$ ano, p. 53).

A partir do apresentado, nota-se que, em especial, o programa de 1925 associou as grandezas não só aos números, mas também às frações ordinárias e decimais e, como 
menciona a citação, no processo de redução e equivalência entre frações. Esse aspecto pode ser justificado pelo avanço das ideias advindas das vagas pedagógicas, que no referido programa pareceu ter ganhado forma acentuada, diante da defesa do ensino em face do uso das coisas, por meios concretos e de situações do cotidiano, o que induziu à inserção das grandezas.

A análise do programa de 1934 não apresenta detalhes sobre o uso dos números como representantes de grandezas para o ensino das frações. $\mathrm{O}$ argumento para tal observação pode dever-se ao fato de que a prescrição de 1934, que se denomina Programas Mínimos, impõe, "como o nome indica, o mínimo de conhecimentos exigíveis de estudantes no fim do ano escolar". Noutras palavras, um programa com redução dos conteúdos a serem ministrados, fator esse que leva ao programa de Iniciação Matemática, como foi denominada a matéria, a supressão de detalhes sobre as grandezas, em relação ao ensino dos números e frações.

No entanto, em sequência, o programa de 1949/50 modificou novamente o status do uso das grandezas: o primeiro e o segundo ano voltaram a destacar as noções das frações ordinárias: metade, terça, quarta e quinta parte, associadas ao ensino de divisão de objetos. Para o primeiro ano, apenas propôs a noção de metade, ao abordar o uso de 4, 10, 12 ou 1 laranja(s), de que se extraía a metade (meio) da quantidade. Como se verifica, as grandezas discretas atrelaram-se à ênfase dada à metade de 4,10, 12 laranjas, porém, quando se toma 1 laranja, a metade é meia laranja, e, neste caso, tinham-se as grandezas contínuas. Em vista desse exemplo, ao que parece, este programa foi o primeiro a associar o ensino de frações com as grandezas discretas, sem, contudo, deixar de lado as grandezas contínuas. E, seguindo esse sentido, sugeriam, para o segundo ano, o ensino das noções de metade, terço, quarto, quinto. Como se destaca,

apesar dos alunos já trazerem alguma noção de fração - metade - do $1^{\circ}$ ano, o estudo deverá ser feito, de início, concretamente, com frutas, botões, pauzinhos, tiras de papel, etc., meios que serão abandonados desde que os alunos tenham a compreensão do assunto e estejam em condições de abstrair [ênfase adicionada]. (2. ${ }^{\circ}$ ano, 1949/50, pp.84-85).

Pelos exemplos dos objetos concretos mencionados na citação, ao que parece o estudo das frações associava-se às duas grandezas: a discreta - no caso dos botões, visto que não faz sentido falar em meio botão, mas, sim, meia dúzia de botões - e das frutas; porém, nessa última, ambas as grandezas podiam ser mobilizadas, como meia dúzia de laranjas e meia laranja. Essa mudança pode ser interpretada em razão das ideias da Escola Nova, que valorizam a ênfase nas situações da vida e a abordagem de centros de interesse dos alunos, como o contexto de feira e comércio, o que - leva a crer - contribuiu para inserção das duas grandezas no ensino de fração.

Percebe-se, então, que nos dois primeiros anos, as grandezas discretas e contínuas foram relacionadas ao ensino das noções de frações ordinárias. Porém, a partir do terceiro ano que o ensino das frações foi tomado de modo aprofundado, pois, como proposto, "estas questões deverão ser ensinadas de modo muito prático, muito seguro, pois é a primeira vez 
que esse estudo vai ser feito de modo sistemático" (3. ano, 1949/50, p. 69). Assim, indicavase ao professor, para o ensino de frações ordinárias: "partir do inteiro; tomará uma folha de papel, por exemplo, um lápis, uma fruta, etc., e dará, então, a noção de que qualquer parte desse inteiro é um pedaço ou fração" (3. ano, 1949/50, p. 85). Essa observação, pelo fato de considerar sempre um elemento (um lápis, uma fruta), leva a crer que o ensino das frações ordinárias foi proposto a partir das grandezas contínuas de maneira implícita. Porém, com a continuidade, nota-se que as grandezas discretas foram abordadas. Para a noção de fração de mais de uma unidade, por exemplo, consideravam-se 12 bolinhas, 8 laranjas e 4 lápis; para explanar sobre a metade, um quarto desses valores.

Para se tratar das frações decimais, o programa de 1949/50 indicava a realização de exercícios concretos com serpentinas, barbantes, tiras de papel, frutas ou massa de modelagem, divididas em dez partes, a fim de que os alunos pudessem notar que, ao dividir uma fruta ou um pano, por exemplo, em dez pedaços iguais, um desses pedaços representava um décimo da fruta ou pano. Destaca-se que a orientação de dividir uma fruta em dez partes talvez tenha sido uma tentativa de que os problemas abordados fossem atrelados a situações mais próximas da vida, mesmo que não fossem tão comuns.

E em seguida, com as mesmas orientações, ou seja, com uso de partições de tiras de papel, se sugeria abordar o centésimo. No caso do milésimo, o ensino se restringia à ideia com números abstratos, haja vista que a divisão de um objeto em 1000 partes não era tão simples. Evidenciam-se ainda no programa os números decimais $(0,5 ; 0,08 ; 0,25)$, e, sob esse aspecto, no programa do $3 .^{\circ}$ ano de 1949 , constata-se que a noção dos números decimais era dada conjuntamente com as frações, como outra forma de representá-los. Havia uma orientação, para o ensino dos números decimais, de que "a explicação de decimais pode ser feita simultaneamente com o sistema métrico - medidas de comprimento - pois é onde melhor se concretiza o seu emprego" (3. ${ }^{\circ}$ ano, 1949, p.95). Entretanto, é mais fácil ver no sistema métrico as divisões em 100 ou 1000 partes, do que a divisão de uma fruta, por exemplo, em 100 partes.

Pode-se dizer que as grandezas são defendidas como agentes de relação com as frações - tanto as ordinárias quanto as decimais. Porém, no caso do $4 .^{\circ}$ ano, a referência ao uso de grandezas começou a diminuir, o ensino das frações ordinárias começou a ser tratado também de modo abstrato. E no $5 .^{\circ}$ ano, seguia o ensino das operações com as frações e a transformação de uma fração ordinária em decimal e vice-versa, porém, embora nas operações com frações haja a sugestão de alguns exemplos com as grandezas ditas contínuas, as situações abstratas começam a ser expostas mais frequentemente.

Pelo apresentado, os programas de 1925 e 1949/50 marcam rupturas no que diz respeito ao ensino das frações, com a presença das grandezas discretas e/ou contínuas adotadas como suporte para abstrair os conceitos de frações ordinárias e decimais. Todavia, as grandezas contínuas que se referem ao sistema métrico pouco se associavam ao campo dos números e das frações, aspecto esse posto apenas no programa de 1949/50, e poucas vezes eram tomadas em relação a tais conceitos. Isso leva a ressaltar que o sistema de pesos e 
medidas era dado em separado, sem propor ligações com outros conteúdos.

\section{Considerações Finais}

A partir do objetivo de compreender como as grandezas são tomadas em relação ao ensino dos números e das frações na matéria Aritmética do ensino primário de São Paulo, 1890-1950, foram considerados como fontes de pesquisa os programas de ensino promulgados a essa época. Desse modo, ao analisar a inserção das grandezas no ensino de saberes aritméticos, percebeu-se que a nomenclatura "grandeza" foi identificada somente no programa de 1925, porém, sem associação ao discreto ou contínuo. Diante da análise supracitada, pode-se evidenciar que as grandezas tiveram modos implícitos de inserção na escola primária.

As grandezas discretas foram postas, nos programas e nos anos escolares, de forma introdutória ao ensino dos números naturais e operações com a representação da quantidade de objetos. Essa observação permite evidenciar que as ideias de números naturais e operações nesse período foram abstraídas das grandezas discretas ou dos números concretos. Haja vista que a abordagem dos números e as operações caminharam para o contexto do abstrato.

Esses indícios podem ser lidos como uma característica da mobilização dos saberes matemáticos, tendo em vista as ideias advindas do método intuitivo, em que se defendia o ensino tendo o concreto como ponto de partida e o percurso em direção à abstração, ou seja, do concreto ao abstrato. Nesse sentido, parece plausível pensar que as grandezas discretas ou os números concretos, em razão dos debates das vagas pedagógicas, demarcaram um papel importante e introdutório para o ensino da noção de números e suas operações.

No ensino das frações, inicialmente percebeu-se que os números abstratos foram priorizados. No entanto, os programas de 1925 e 1949/50 demonstraram distinções, pois, como constatado, as grandezas discretas e/ou contínuas foram chamadas a integrar aos seus ensinos. Esses dois programas, em que se evidenciaram mais claramente as noções de grandezas, contribuem para reforçar o papel das grandezas no ensino primário, visto que os exemplos de partições de frutas e objetos, ou associações a meio litro, meio quilo falam de perto com o cotidiano das crianças. Não obstante, pode-se dizer que tal abordagem não é uma ruptura em relação ao método intuitivo. Ao que parece, com os discursos da Escola Nova se propagou um maior debate acerca da importância da inserção de situações da vida prática (mais complexa que somente objetos) na escola, o que se reflete nas proposições das frações com relação às grandezas contínuas e discretas.

Dessas constatações pode-se concluir que as grandezas discretas e contínuas, mesmo que de modo implícito, foram se constituindo ao longo do ensino primário, sendo consideradas no ensino dos saberes aritméticos. Porém o programa de 1949/50, mesmo de forma tênue, parece ter sido o início da sistematização das grandezas na escola primária, haja vista que nesse programa partia-se dos conceitos de quantidade, tamanho e peso, antes mesmo de abordar conceitos de números, operações e frações. 
DOI: https://doi.org/10.20396/zet.v26i3.8650703

Como notado, esta análise considerou apenas os programas de ensino de São Paulo, o que resultou numa leitura limitada, pois alguns programas apresentam apenas o sumário da matéria. Por esse motivo, com o exame de manuais didáticos pode-se elucidar com mais detalhes a inserção das grandezas e as suas relações no ensino dos números e frações. Esse aspecto poderá ser (re)considerado em análises futuras, de modo a caracterizar com mais detalhes a relação das grandezas com o ensino de saberes aritméticos, números e frações.

\section{Referências}

Bloch, M. (1998). Nell'Apologia della storia o Mestiere di storico. Torino: Einaudi.

Carvalho, M. M. C. (2000). Modernidade pedagógica e modelos de formação docente. São Paulo em Perspectiva, 14(1), 111-120.

Chambris, C. (2007). Petite histoire des rapports entre grandeurs et numerique dans les programmes de l'ecole primaire. Reperes - IREM, 69, 5-31.

Chervel, A. (1990). História das disciplinas escolares: reflexões sobre um campo de pesquisa. Teoria \& Educação, 2, 177-229.

Hofstetter, R., \& Schneuwly, B. (2017). Introduction - Savoirs en (trans)formation - Au coeur des professions de l'enseignement et de la formation. In: R. Hofstetter, \& W. R. Valente (Orgs.). Saberes em (trans)formação: tema central da formação de professores. (pp. 113-172). São Paulo: Livraria da Física.

Lourenço Filho, M. B. (1930). Introducção ao estudo da Escola Nova (Bibliotheca de Educação, vol. 10). São Paulo: Companhia Melhoramentos de S. Paulo.

Noirfalise, R. (2007). Calculer avec les grandeurs: l'usage des unites dans les calculs. Reperes - IREM, 68, 21-32.

Pinheiro, N. V. L. (2013). Escolas de práticas pedagógicas inovadoras: intuição, escolanovismo e matemática moderna nos primeiros anos escolares. Dissertação de Mestrado em Ciências. Guarulhos: Universidade Federal de São Paulo. Retirado em 15 de setembro, 2017, de: https://repositorio.ufsc.br/handle/123456789/104911.

Programa das Escolas Preliminares. (1894). Retirado em 15 de setembro, 2017, de: https://repositorio.ufsc.br/handle/123456789/99544.

Programa de Ensino para os Grupos Escolares e Escolas-Modelos. (1905). Retirado em 15 de setembro, 2017, de: https://repositorio.ufsc.br/handle/123456789/99554.

Programa de Ensino para os Grupos Escolares. (1918). Retirado em 15 de setembro, 2017, de: https://repositorio.ufsc.br/handle/123456789/99555.

Programa de Ensino do Curso Primário para os Grupos Escolares e Escolas Isoladas (1925). Retirado em 15 de setembro, 2017, de: http://repositorio.ufsc.br/xmlui/handle/ $123456789 / 99651$.

Programas Mínimos do Curso Primário para os Grupos Escolares. (1934). Retirado em 15 de setembro, 2017, de: http://repositorio.ufsc.br/xmlui/handle/123456789/99652.

Programas para o Ensino Primário Fundamental, ato n. 17, $1^{\circ}$ ano, 1949. (1949a). Retirado em 15 de setembro, 2017, de: https://repositorio.ufsc.br/handle/123456789/99656. 
Programas para o Ensino Primário Fundamental, ato n. 24, $2^{\circ}$ ano, 1949. (1949b). Retirado em 15 de setembro, 2017, de: http://repositorio.ufsc.br/xmlui/handle/123456789/99657.

Programas para o Ensino Primário Fundamental, ato n. 46, $3^{\circ}$ ano, 1949. (1949c). Retirado em 15 de setembro, 2017, https://repositorio.ufsc.br/xmlui/handle/123456789/104783.

Programas para o Ensino Primário Fundamental, ato n. 5, $4^{o}$ ano, 1950. (1950a). Retirado em 15 de setembro, 2017, de: https://repositorio.ufsc.br/xmlui/handle/123456789/104786.

Programas para o Ensino Primário Fundamental, ato n. 35, $5^{\circ}$ ano, 1950. (1950b). Retirado em 15 de setembro, 2017, de: https://repositorio.ufsc.br/xmlui/handle/123456789/104789.

Souza, R. F. (2000). Inovação educacional no século XIX: A construção do currículo da escola primária no Brasil. Cadernos Cedes, 20(51), 9-28.

Souza, R. F. (2009). Alicerces da Pátria: História da escola no estado de São Paulo (18901976). Campinas/São Paulo: Mercado de Letras.

Valente, W. R. (2015). A constituição do elementar matemático: uma análise de programas de ensino (São Paulo, 1890-1950). Educação Unisinos (Online), 19(2), 196-205. 